\title{
AN INNOVATIVE WAY FOR COMPUTERIZED SMITH CHART GENERATION AND TRANSMISSION LINE PROBLEM SOLVING
}

\author{
Sangita Choudhury ${ }^{1}$, Namrata Kataki ${ }^{2}$ \\ ${ }^{\text {I}}$ Assistant Professor, EE, GIMT, Guwahati, Assam, India \\ ${ }^{2}$ Assistant Professor, ECE, GIMT, Guwahati, Assam, India
}

\begin{abstract}
The Smith chart is one of the most useful graphical tools for high frequency circuit applications. It provides a clever way to visualize complex functions and solving problems with transmission lines and matching circuits. Here a computer-assisted learning technique is presented using C language for making lively and dynamic problem solving interface, by which one can implement the smith chart and solve problems easily related to transmission line and matching circuit. The concept of explaining the use of an important old tool like the Smith Chart, using modern tool like C to explain the use of the Smith Chart represents a prime example of the melding of the traditional and the leading edge. Here, we have solved some of the most common transmission line problems using this software and have compared the results of both experimental calculations as well as manual calculations.
\end{abstract}

Keywords: Smith chart, Transmission line, Impedance matching Reflection co-efficient, VSWR, Normalized Impedance, Normalized admittance

\section{INTRODUCTION}

Smith chart is a graphical tool for solving transmission line problems which was developed by P. H. Smith [1]. It reveals graphically the complex impedance anywhere along a line. The smith chart is very useful when solving transmission problems. The real utility of the Smith chart, it can be used to convert from reflection coefficients to normalized impedances (or admittances), and vice versa [2]. The mathematics of transmission lines becomes cumbersome at times, especially when dealing with complex impedances and nonstandard situations. In 1939, Phillip H. Smith published a graphical device for solving these problems, the Smith Chart. It consists of a series of overlapping orthogonal circles that intersect each other at right angles. These sets of orthogonal circles make up the basic structure of the Smith chart and are shown in Fig. 1[3]. When illustrating fundamental concepts the Smith chart is the ideal tool, especially at the level where concepts are being explained to students and when they are exposed to these concepts for the first time. The Smith chart provides an extremely useful way of visualizing transmission line phenomenon, and so is also important for pedagogical reasons. Microwave and RF engineers can develop intuition about transmission line impedance matching problems by learning to think in terms of the Smith chart [4]. In the modern age, using the Smith chart to perform calculations has gone the way of the slide rule; such calculations are best done using a computer program. However, the utility of the Smith chart to enhance the understanding of complex impedances has not diminished. Indeed, use of the Smith chart has grown over the decades since its invention. The Smith chart remains one of the most widely used nomographs used in the practice of electrical engineering [5].

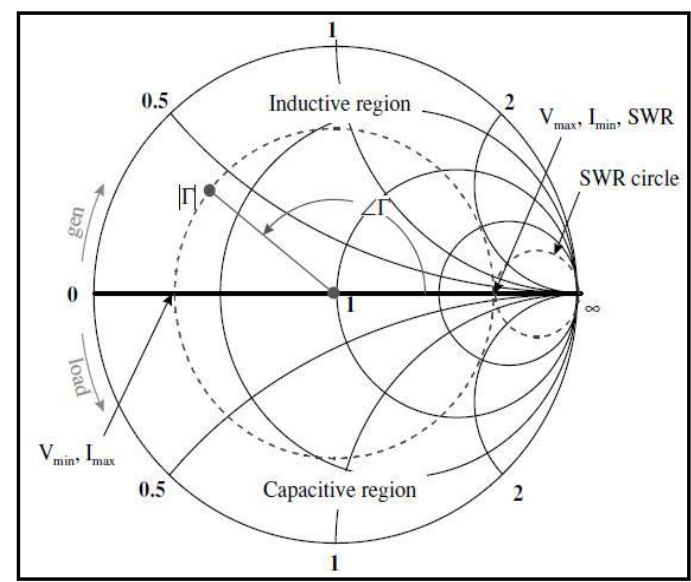

Fig-1: A Smith chart

\section{TRANSMISSION LINE PARAMETERS}

The following transmission line parameters are associated with this method-

\subsection{Reflection Co-efficient}

The reflection co-efficient is used in physics and electrical engineering when wave propagation in a medium containing discontinuity is considered. It is designated by $\Gamma$ (gamma) and is defined as-

$\Gamma=$ reflected voltage or current/incident voltage or current

$=\mathrm{V}_{\text {ref }} / \mathrm{V}_{\text {inc }}$

$=\mathrm{I}_{\mathrm{ref}} / \mathrm{I}_{\text {inc }}$ 


\subsection{Transmission Co-efficient}

A transmission line terminated in its characteristic impedance $Z_{o}$ is called a properly terminated line. According to the principle of conservation of energy, the incident power minus the reflected power must be equal to the power transmitted to the load. This can be expressed as

$$
1-\Gamma_{\mathrm{r}}^{2}=\left(\mathrm{Z}_{\mathrm{o}} / \mathrm{Z}_{\mathrm{r}}\right) \cdot \mathrm{T}^{2}
$$

where $\mathrm{T}$ is the transmission coefficient and is defined as-

$\mathrm{T}=$ transmitted voltage or current $/$ incident voltage or current

$=\mathbf{V}_{\mathrm{tr}} / \mathbf{V}_{\mathrm{inc}}$

$=\mathbf{I}_{\mathrm{tr}} / \mathbf{I}_{\mathrm{inc}}$

\subsection{Voltage Standing Wave ratio}

The ratio of the maximum of the voltage standing-wave pattern to the minimum is defined as the voltage standing wave ratio $(\rho)$ and is given by-

$\rho=\mathrm{VSWR}=|\mathrm{Vmax}| /|\mathrm{Vmin}|$

Also, $\rho=[(1+|\Gamma|) /(1-|\Gamma|)]$

\subsection{Normalized Impedance}

The normalized impedance with characteristic impedance (Zo) may be calculated by dividing the load impedance $\left(Z_{L}\right)$ by the characteristic impedance i.e. $z_{L}=Z_{L} / Z_{0}$

For a lossless transmission line-

The maximum normalized impedance, $Z_{\max }=1+|\Gamma| / 1-|\Gamma|$

\subsection{Normalized Admittance}

The normalized is the reciprocal of normalized impedance. i.e. $\mathrm{y}=\mathrm{Z}_{\mathrm{O}} / Z_{L}=1 / z_{L}$

Actual admittance $=y / Z o$

\subsection{Stub}

Impedance matching can be achieved by inserting a section of short circuited transmission line (in shunt with the main line) in between the load and source is called stub. This process is called stub-matching.

\section{MATHEMATICAL FORMULATION}

The following formulas are used in implementation of the software [6]-

(1) characteristic impedance $Z_{0}=R_{0}+\mathrm{j} X_{0}$

(2) load impedance $Z_{L}=R_{L}+\mathrm{j} X_{L}$

(3)

$$
\Gamma=\frac{Z_{L}-Z_{0}}{Z_{L}+Z_{0}}=\frac{z_{L}-1}{z_{L}+1}
$$

where normalized load impedance, $z_{L}=Z_{L} / Z_{0}$

(4) $\Gamma=\Gamma \mathrm{r}+\mathrm{j} \Gamma_{\mathrm{i}}=|\Gamma| \mathrm{e}^{\mathrm{j} \theta}$

(5) normalized load impedance,

$$
\begin{aligned}
r_{L}+\mathrm{jx}_{\mathrm{L}}= & \frac{1+\Gamma_{r}+j \Gamma_{i}}{1-\Gamma_{r}-j \Gamma_{i}} \\
& =\frac{1-\Gamma_{r}^{2}-\Gamma_{i}^{2}}{\left(1-\Gamma_{r}\right)^{2}+\Gamma_{i}^{2}} \\
& +j \frac{2 \Gamma_{i}}{\left(1-\Gamma_{r}\right)^{2}+\Gamma_{i}{ }^{2}}
\end{aligned}
$$

where $\Gamma \mathrm{r}, \Gamma_{\mathrm{i}}$ are real and imaginary part of reflection coefficient respectively and $r_{L}, x_{L}$ are real and imaginary part of normalized impedance respectively

(6) Equations for drawing constant resistance and constant reactance circle-

$$
\begin{aligned}
\left(\Gamma_{r}-\frac{r_{L}}{r_{L}+1}\right)^{2}+\left(\Gamma_{i}-0\right)^{2} & =\left(\frac{1}{r_{L}+1}\right)^{2} \\
\left(\Gamma_{r}-1\right)^{2}+\left(\Gamma_{i}-\frac{1}{x_{L}}\right)^{2} & =\left(\frac{1}{x_{L}}\right)^{2}
\end{aligned}
$$

\section{SOFTWARE IMPLEMENTATION STEPS}

\subsection{Preparation of Smith Chart}

- A circle is drawn with a horizontal line passing through its centre

- The circles of constant resistance and conductance are drawn

- The lines of constant reactance and susceptance are drawn

- $\quad$ Two more outer circles (inner wavescale and outer wavescale) are drawn and marked

\subsection{To Determine Reflection Co-efficient}

- $\quad$ The input values are load resistance, load reactance and characteristic impedance

- $\quad$ After that the normalized resistance and normalized reactance are calculated

- Then the constant resistance and constant reactance circles are drawn

- The magnitude of reflection coefficient is calculated from the origin to the point of intersection of the two circles

- $\quad$ The angle is calculated from the slope of the line

\subsection{To Determine VSWR}

- Repeat the steps of determination of reflection coefficient as given in (4.2)

- $\quad$ Taking the reflection coefficient as the radius, the VSWR circle is drawn with origin at the centre of the screen

- Wherever the circle cuts the horizontal line in the right hand side, it is the location of VSWR and in the left hand side, it is $1 /$ VSWR

\subsection{To calculate Admittance Point}

- Repeat the steps of calculation of VSWR as given in (4.3) 
- The line drawn from the origin to the point of intersection of the two circles to find magnitude of reflection coefficient is extended in opposite direction and finds the point where it cuts the VSWR circle

- Then the normalized conductance and normalized susceptance is calculated. This gives the normalized admittance point

\subsection{To Calculate Zmin and Zmax}

- Repeat the steps of determination of reflection coefficient as described in (4.2)

- $\quad$ Taking the reflection coefficient as the radius, the VSWR circle is drawn with origin at the centre of the screen

- Wherever the circle cuts the horizontal line in the right hand side, it is the location of $\mathrm{Zmax}$ and in the left hand side, it is Zmin

\subsection{To Calculate Voltage Minimum (Vmin)}

- Repeat the steps of determination of reflection coefficient as described in (4.2)

- The location of the reflection co-efficient point is found from the wavescale and deducted from the total wavescale value i.e. $0.5 \lambda$. This gives the location of voltage minimum

\subsection{To Calculate Input Impedance and Admittance}

- Repeat the steps of determination of reflection coefficient as described in (4.2)

- The reflection coefficient as the radius, the VSWR circle is drawn with origin at the centre of the screen

- The location of the above point is found from the wavescale and the given distance is added to this value and new location is found. Now a line is drawn from this point to the centre of the VSWR circle. The point of intersection of the line with VSWR circle is determined. Now, resistance and reactance of the point are found. This gives the input impedance

- $\quad$ Similarly input admittance is also determined

\subsection{To Calculate Location of Stub}

- The location of the admittance point is found as done in step 4.4

- The location of the admittance point is found from the wavescale. This gives the location of the load

- The point at which VSWR circle cuts the unit conductance circle is determined. The location of the above point is found from the wavescale. This gives the location of the stub

\subsection{To Calculate Location at which Real Part of the}

Admittance Equals the Line Characteristic

- The input admittance point is determined as mentioned above. Location of this point is found from wavescale

- The point at which VSWR circle cuts the unit conductance circle is determined. The location of the above point is found from the wavescale

- $\quad$ The difference between the abobe two points gives the location nearest to the load at which the real part of the admittance equals the line characteristic admittance

\subsection{To Continue or Exit}

- $\quad$ The program asks the user if he wants to continue with with the program or not by choosing the option y (to continue) and $\mathrm{n}$ (to exit)

\section{SOFTWARE APPLICATIONS}

The implemented software can be used in the following cases-

- Determination of reflection co efficient from a given load impedance

- Determination of VSWR from a given load impedance

- Determination of load admittance from a given load impedance

- Determination of $\mathrm{Zmax}$ and $\mathrm{Zmin}$ (maximum impedance and minimum impedance respectively)

- $\quad$ Determination of distance of first voltage minimum of the standing wave pattern from a given load impedance

- Determination of input impedance and input admittance from a given load impedance at a given distance

- Determination of location of the point at which real part of the line admittance is equal to the line characteristic impedance from a given load impedance

- Determination of location of load and stub from a given load impedance and operating frequency

\section{EXPERIMENTAL RESULTS}

In this column various transmission line related problem solving results (found by both experimentally and manually) along with software outputs are listed in table (18) and figure (2-9).

Table -1

\begin{tabular}{|l|l|}
\hline Determination of Reflection Co-efficient \\
\hline Given Data & $\begin{array}{l}\text { load Impedance, } \mathrm{Z}=(27.5+\mathrm{j} 80) \Omega \\
\text { Characteristic impedance, } \mathrm{Zo}=50 \Omega\end{array}$ \\
\hline $\begin{array}{l}\text { Experimental } \\
\text { results }\end{array}$ & $0.746<59.8^{0}$ \\
\hline $\begin{array}{l}\text { Manually } \\
\text { calculated } \\
\text { value }\end{array}$ & $0.75<60^{0}$ \\
\hline Figure No & Fig 2 \\
\hline
\end{tabular}

Impedance 
Table -2

\begin{tabular}{|l|l|}
\hline \multicolumn{2}{|l|}{ Determination of VSWR } \\
\hline Given Data & $\begin{array}{l}\text { Load Impedance, } \mathrm{Z}=(50-\mathrm{j} 100) \Omega \\
\text { Characteristic impedance, } \mathrm{Zo}=75 \Omega\end{array}$ \\
\hline $\begin{array}{l}\text { Experimental } \\
\text { results of the } \\
\text { software }\end{array}$ & 4.616 \\
\hline $\begin{array}{l}\text { Manually } \\
\text { calculated value }\end{array}$ & 4.6 \\
\hline Figure No & Fig 3 \\
\hline
\end{tabular}

Table -3

\begin{tabular}{|l|l|}
\hline \multicolumn{2}{|l|}{ Determination of Load admittance } \\
\hline Given Data & $\begin{array}{l}\text { load Impedance, } \mathrm{Z}=(50+\mathrm{j} 100) \Omega \\
\text { characteristic impedance, } \mathrm{Zo}=50 \Omega\end{array}$ \\
\hline $\begin{array}{l}\text { Experimental } \\
\text { results of the } \\
\text { software }\end{array}$ & $\begin{array}{l}\text { normalized admittance }=(0.2-\mathrm{j} 0.4) \\
\text { actual admittance }=(0.004-\mathrm{j} 0.008) \text { mho }\end{array}$ \\
\hline $\begin{array}{l}\text { Manually } \\
\text { calculated } \\
\text { value }\end{array}$ & $\begin{array}{l}\text { normalized admittance }=(0.2-\mathrm{j} 0.4) \\
\text { actual admittance }=(0.004-\mathrm{j} 0.008) \text { mho }\end{array}$ \\
\hline Figure No & Fig 4 \\
\hline
\end{tabular}

Table -4

Determination of maximum and minimum impedance (Zmax and Zmin)

\begin{tabular}{|l|l|}
\hline Given Data & $\begin{array}{l}\text { load Impedance, } \mathrm{Z}=(50-\mathrm{j} 100) \Omega \\
\text { characteristic impedance, } \mathrm{Zo}=75 \Omega\end{array}$ \\
\hline $\begin{array}{l}\text { Experimental } \\
\text { results of the } \\
\text { software }\end{array}$ & $\begin{array}{l}\mathrm{Zmax}=4.61 \\
\mathrm{Zmin}=0.216\end{array}$ \\
\hline $\begin{array}{l}\text { Manually } \\
\text { calculated value }\end{array}$ & $\mathrm{Zmax}=4.6$ \\
\hline Figure No & Fig 5 \\
\hline
\end{tabular}

Table -5

Determination of distance of $1^{\text {st }}$ voltage minimum of the standing wave pattern from a given load impedance

\begin{tabular}{|l|l|}
\hline Given Data & $\begin{array}{l}\text { load Impedance, } \mathrm{Z}=(150-\mathrm{j} 20) \Omega \\
\text { characteristic impedance, } \mathrm{Zo}=50 \Omega\end{array}$ \\
\hline $\begin{array}{l}\text { Experimental } \\
\text { results of the } \\
\text { software }\end{array}$ & $\begin{array}{l}\text { distance of first voltage minimum }= \\
0.065 \lambda\end{array}$ \\
\hline $\begin{array}{l}\text { Manually } \\
\text { calculated value }\end{array}$ & $\begin{array}{l}\text { distance of first voltage minimum }= \\
0.065 \lambda\end{array}$ \\
\hline Figure No & Fig 6 \\
\hline
\end{tabular}

\section{Table -6}

\begin{tabular}{|l|l|}
\hline $\begin{array}{l}\text { Determination of input impedancee and input admittance } \\
\text { from a given load impedance at a given distance }\end{array}$ \\
\hline Given Data & $\begin{array}{l}\text { load Impedance, } \mathrm{Z}=(150-\mathrm{j} 20) \Omega \\
\text { characteristic impedance, } \mathrm{Zo}=50 \Omega \\
\text { given distance }=0.05 \lambda\end{array}$ \\
\hline $\begin{array}{l}\text { Experimental } \\
\text { results of the } \\
\text { software }\end{array}$ & $\begin{array}{l}\text { normalized impedance }=(0.257-\mathrm{j} 0.08) \\
\text { normalized admittance }=(3.4+\mathrm{j} 1.19)\end{array}$ \\
& $\begin{array}{l}\text { actual impedance }=(12.89-\mathrm{j} 4.44) \lambda \\
\text { actual admittance }=(0.069+\mathrm{j} 0.023) \\
\text { mho }\end{array}$ \\
\hline $\begin{array}{l}\text { Manually } \\
\text { calculated value }\end{array}$ & $\begin{array}{l}\text { normalized impedance }=(0.22-\mathrm{j} 0.1) \\
\text { normalized admittance }=(3.5+\mathrm{j} 1.1)\end{array}$ \\
& $\begin{array}{l}\text { actual impedance }=(13.5-\mathrm{j} 5) \lambda \\
\text { actual admittance }=(0.065+\mathrm{j} 0.022) \\
\text { mho }\end{array}$ \\
\hline Figure No & Fig 7 \\
\hline
\end{tabular}

Table -7

Determination of location of the point at which real part of line admittance is equal to the line characteristic impedance from a given load impedance

\begin{tabular}{|l|l|}
\hline Given Data & $\begin{array}{l}\text { load Impedance, } \mathrm{Z}=(15-\mathrm{j} 20) \Omega \\
\text { characteristic impedance, } \mathrm{Z}_{\mathrm{o}}=50 \Omega\end{array}$ \\
\hline $\begin{array}{l}\text { Experimental } \\
\text { results of the } \\
\text { software }\end{array}$ & $0.1396 \lambda$ \\
\hline $\begin{array}{l}\text { Manually } \\
\text { calculated value }\end{array}$ & $0.14 \lambda$ \\
\hline Figure No & Fig 8 \\
\hline
\end{tabular}

Table -8

Determination of location of load and stub and also the input susceptance of the stub from a given load impedance and operating frequency

\begin{tabular}{|l|l|}
\hline Given Data & $\begin{array}{l}\text { load Impedance, } \mathrm{Z}=(30-\mathrm{j} 40) \Omega \\
\text { characteristic impedance, } \mathrm{Zo}=50 \Omega\end{array}$ \\
\hline $\begin{array}{l}\text { Experimental } \\
\text { results of the } \\
\text { software }\end{array}$ & $\begin{array}{l}\text { location of the load }=0.1249 \lambda \\
\text { location of the stub }=0.166 \lambda \\
\text { location of the stub from load }=0.0083 \mathrm{~m} \\
\text { input susceptance of the stub=-0.0230 } \\
\text { mho }\end{array}$ \\
\hline $\begin{array}{l}\text { Manually } \\
\text { calculated } \\
\text { value }\end{array}$ & $\begin{array}{l}\text { location of the load }=0.125 \lambda \\
\text { location of the stub }=0.165 \lambda \\
\text { location of the stub from load }=0.008 \mathrm{~m} \\
\text { input susceptance of the stub=-0.0236 } \\
\text { mho }\end{array}$ \\
\hline Figure No & Fig 9 \\
\hline
\end{tabular}




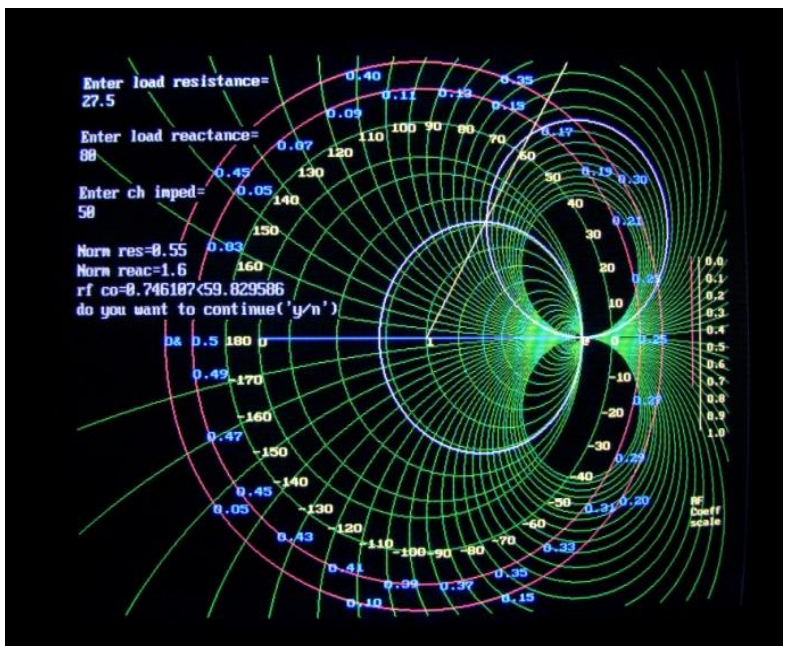

Fig -2: Software output for determining reflection coefficient

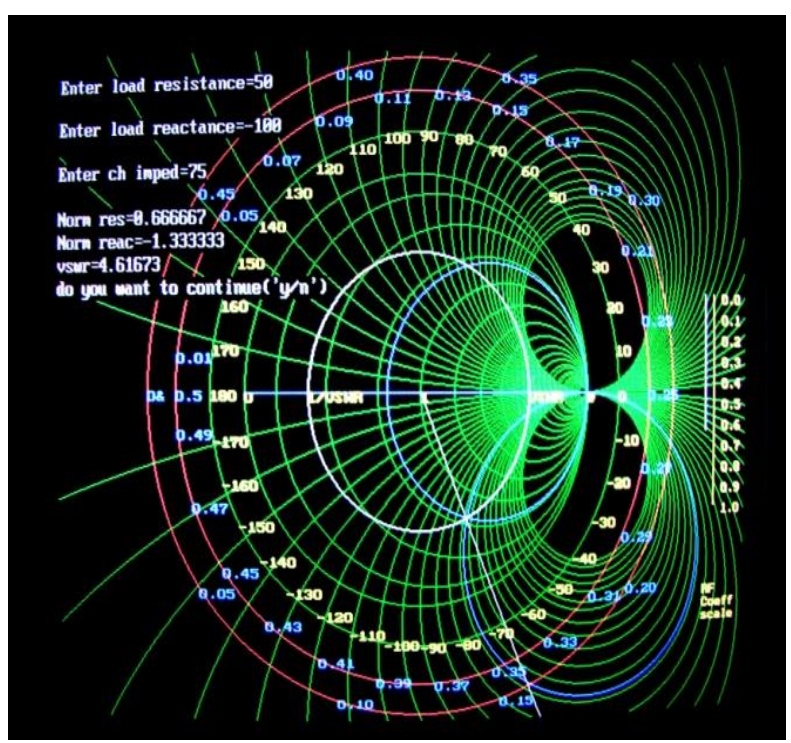

Fig -3: Software output for determining VSWR

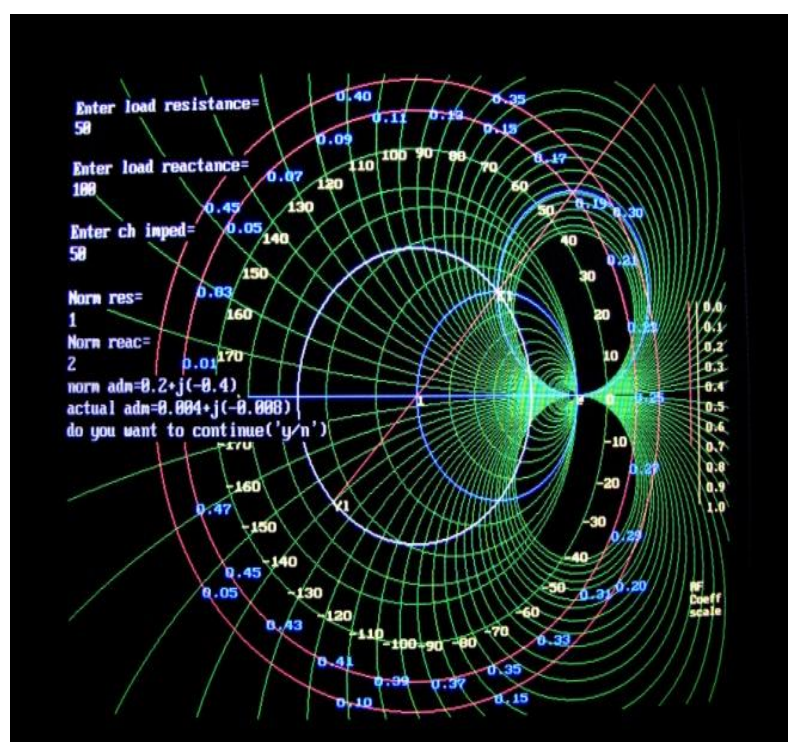

Fig -4: Software output for determining load admittance

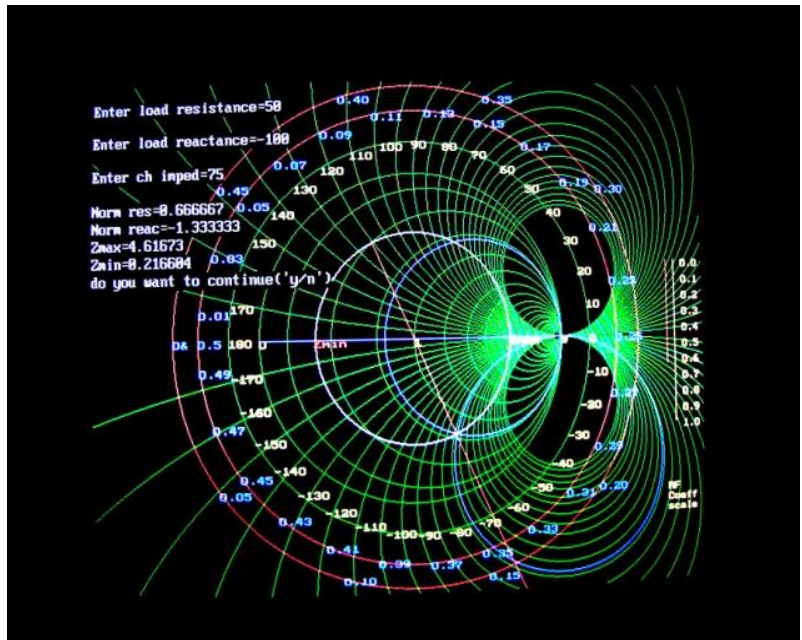

Fig -5: Software output for determining maximum and minimum impedance

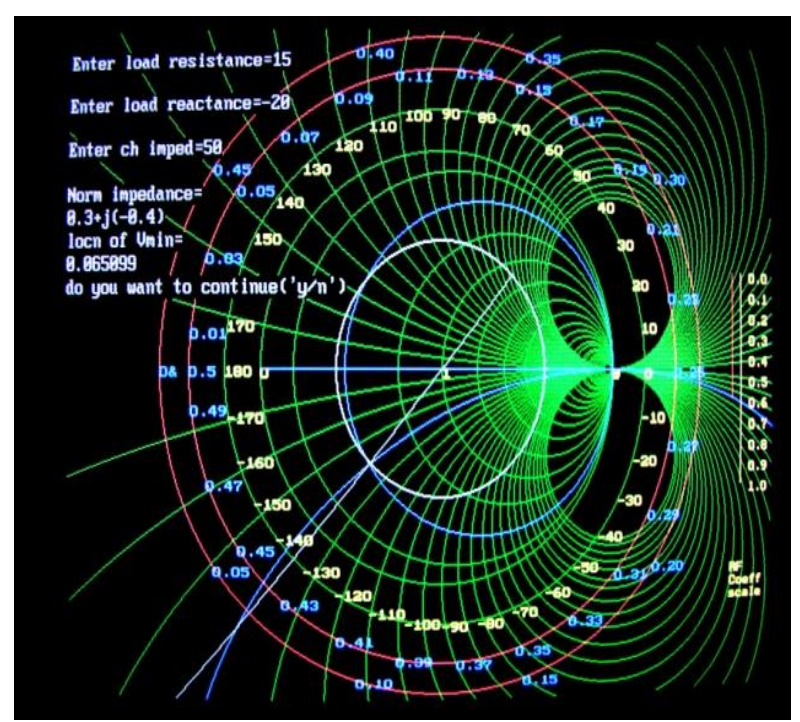

Fig -6: Software output for determining distance of first voltage minimum from a given load impedance

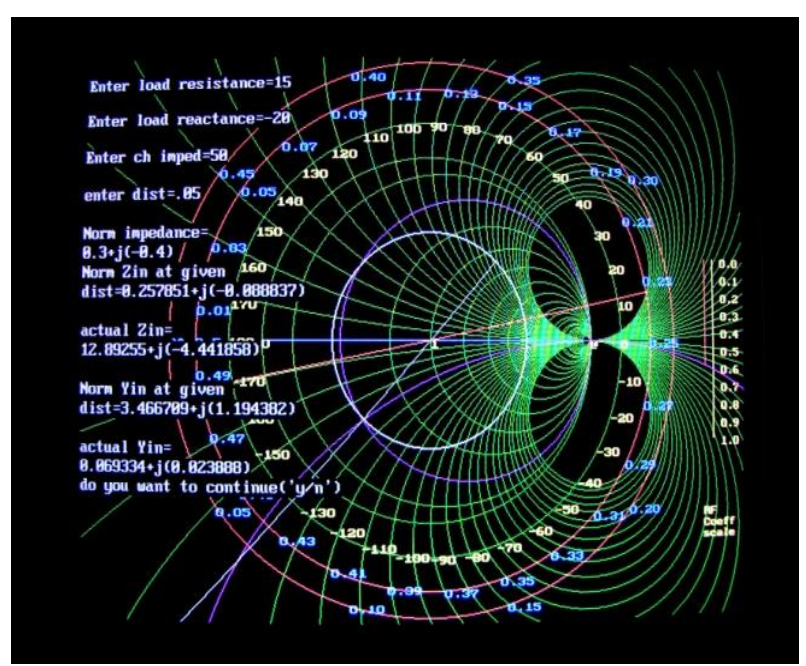

Fig -7: Software output for determining input impedance and input admittance from a given load impedance at a given distance 


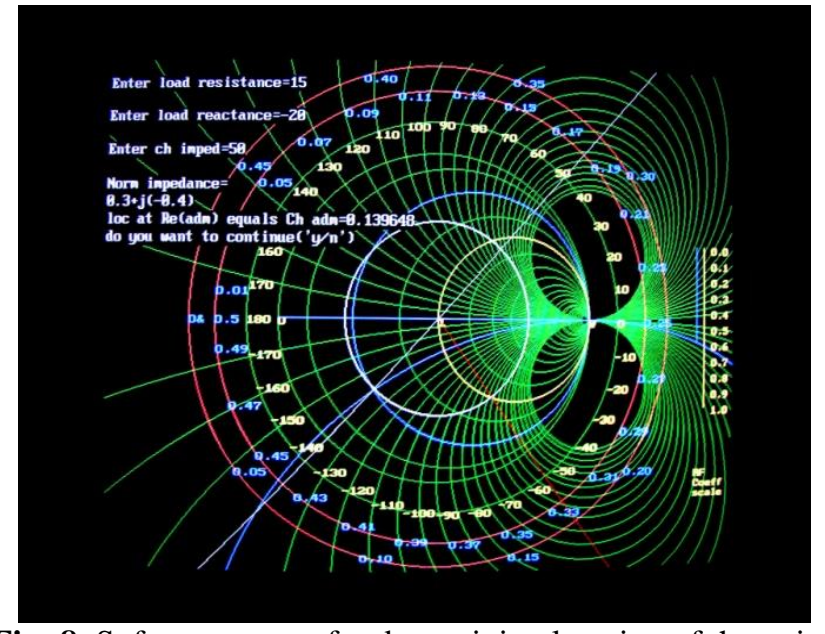

Fig -8: Software output for determining location of the point at which real part of line admittance is equal to the line characteristic impedance from a given load impedance

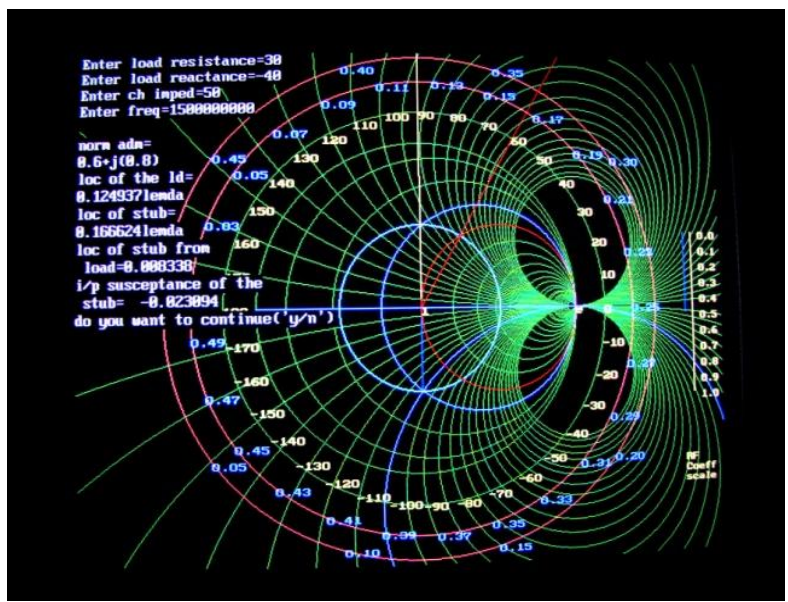

Fig -9: Software output for determining location of load and stub and also the input susceptance of the stub from a given load impedance and operating frequency

\section{CONCLUSIONS}

The study of transmission lines is basic in undergraduate electrical and electronics engineering education. In relevant courses, a key subject is the Smith chart, which is a graphical device providing insight [7]. Understanding the Smith chart is still important nowadays, despite the present generalization of personal computers and powerful calculators. It is easy to plug a few numbers into a program and have it spit out solutions. When the solutions are complex and multifaceted, having a computer to do the grunt work is especially handy. However, knowing the underlying theory and principles that have been ported to computer platforms, and where they came from, makes the engineer or designer a more well-rounded and confident professional, and makes the results more reliable. Moreover it is interesting to note that these kinds of graphical tools are still useful now adays [8]. This software provides a powerful computation and display platform by means of which fundamental and advanced concepts relating to transmission lines can be understood and implemented [9]. This software is very simple for beginners, cost effective, reliable and easy to handle. It also requires very less time to execute. Furthermore, the computations are more accurate and the results can be displayed and interpreted in a more effective manner.

\section{REFERENCES}

[1]. P. H. Smith Transmission line calculator//Electronics, 1939-Vol.12-No.1-P.39-42.

[2]. R. Rajoria, "Patch Antenna using Metamaterial Structure for Performance Specification", IJESRT, 3(4), April-2014.

[3]. J. J. Carr, Practical Antenna Handbook, fourth edition, McGraw-Hill, New York, 2001.

[4]. David M. Pozar, Microwave and RF Design of Wireless Systems, First Edition. New York: John Wiley \& Sons (Publishers), 2001.

[5]. Ward Harriman-AE6TY, "A New Program for the Venerable Smith Chart”, The QRP Quarterly, Winter 2011, page 47-53, www.qrparci.org.

[6]. Samuel Y. Liao, Microwave devices and circuits, third edition, Prentice Hall Publication, 1996.

[7]. G. Fikioris, 'Analytical studies supplementing the Smith Chart”, IEEE Transaction, Vol. 47, Issue.2, May-2004.

[8]. Jose R. Pereira and Pedro Pinho, "Using the Smith Chart in an E-Learning Approach", E-LearningOrganizational Infrastructure and Tools for Specific Areas, Prof. Adilson Guelfi (Ed.), 2012, ISBN: 978- 953- 51- 00539.

[9]. Fong Mak and Ram Sundaram, "A Matlab-Based Teaching Of The Two-Stub Smith Chart Application For Electromagnetics Class", 38th ASEE/IEEE Frontiers in Education Conference, October 22 - 25, 2008, Saratoga Springs, NY. 